\begin{tabular}{|c|c|c|}
\hline Case ReD & \multicolumn{2}{|c|}{ Case Rep Gastroenterol 2017;11:127-133 } \\
\hline Gastroenterology & $\begin{array}{l}\text { DOI: } 10.1159 / 000455940 \\
\text { Published online: VIarch 3, } 2017\end{array}$ & $\begin{array}{l}\text { (c) } 2017 \text { The Author(s)Published by S. } \\
\text { Karger AG, Basel } \\
\text { www.karger.com/crg }\end{array}$ \\
\hline & $\begin{array}{l}\text { This article is licensed under } \mathrm{t} \\
\text { International License (CC BY-N } \\
\text { Usage and distribution for comm }\end{array}$ & $\begin{array}{l}\text { nons Attribution-NonCommercial } 4.0 \\
\text { ger.com/Services/OpenAccessLicense) } \\
\text { uires written permission. }\end{array}$ \\
\hline
\end{tabular}

Single Case

\title{
Shock due to Splenic Injury after Colonoscopy
}

\author{
Erol G. Nallayici ${ }^{a}$ Reinier de Groot ${ }^{a}$ René A.A. van Zanten ${ }^{b}$ \\ Martijn F. Lutke Holzik ${ }^{a}$ \\ ${ }^{a}$ Department of Surgery, Ziekenhuisgroep Twente (ZGT), Almelo, The Netherlands; \\ ${ }^{b}$ Department of Gastroenterology, Ziekenhuisgroep Twente (ZGT), Almelo, The \\ Netherlands
}

\section{Keywords}

Splenic injury · Colonoscopy · Complication · Rupture $\cdot$ Haematoma $\cdot$ Splenectomy

\begin{abstract}
Colonoscopy is a common and increasingly performed procedure. It is used both as a diagnostic and therapeutic modality. Splenic injury after colonoscopy is a rare, yet lifethreatening complication, most often caused by traction on the splenocolic ligament or excessive manipulation during the procedure. Although non-operative treatment is preferred upon splenic injury, early surgical or radiological intervention may be necessary in specific cases, for example in case of haemodynamic instability. A 71-year-old Caucasian man was referred to our emergency room due to shock after colonoscopy 2 days earlier. A computed tomography scan showed splenic rupture with active intra-abdominal, venous blood loss, and microperforation of the colon. An immediate splenectomy and colon repair were performed through laparotomy. After 6 days, the patient was discharged from hospital in good health. Although splenic rupture is a rare complication of colonoscopy, patients with abdominal pain and/or shock should be checked for complications such as splenic injury and colon perforation.




\section{Case Reports in Gastroenterology}

Case Rep Gastroenterol 2017;11:127-133

(C) 2017 The Author(s). Published by S. Karger AG, Basel www.karger.com/crg

Nallayici et al.: Shock due to Splenic Injury after Colonoscopy

\section{Introduction}

Colonoscopy is an increasingly performed procedure. The most common reported complications are intraluminal bleeding and (micro)perforation of the colon [1]. Splenic injury upon colonoscopy, as initially described by Wherry and Zehner [2], is a rare, yet lifethreatening complication. The most common aetiology is traction on the splenocolic ligament or excess manipulation during the procedure to advance the scope beyond the splenic flexure [3]. Because of its rareness (incidence $=0.00005-0.017 \%$; mortality rate $=5 \%$ [1]), diagnosis is often delayed. Consequently, this could lead to an increased risk of morbidity as well as mortality. Early symptoms are often attributed to air insufflation as a result of chronic distension and postpolypectomy serositis. It is often masked by sedation, analgesia, older age, and impaired mental state [1]. When it comes to treatment of splenic injury after colonoscopy, the majority of the reported cases were managed by surgical splenectomy; therefore, early surgical consultation is warranted especially in the case of unstable patients [4]. In haemodynamically stable patients non-operative management is the treatment of choice. Non-operative treatment consists of observation or selective arterial splenic embolization. With the increasing number of colonoscopies performed, it is expected that this complication will be more frequent in the coming years.

\section{Case Report}

A 71-year-old Caucasian man was referred to the emergency room in a clinical state of shock (anxious, heart rate 126 [per minute], respiratory rate 22 [per minute], blood pressure $78 / 49 \mathrm{~mm} \mathrm{Hg}$ ) and abdominal pain. The physical examination revealed peritonitis with decreased bowel sounds, painful percussion and tenderness, and pain in all quadrants of the abdomen. Kehr's sign was not tested during physical examination. The haemoglobin count was markedly decreased (Table 1). Two days earlier, an experienced endoscopist performed a colonoscopy as part of a screening programme for colorectal cancer. During the procedure, 7 (benign) polyps were removed. One of the polyps was situated near the splenic flexure.

His medical history showed a carotid endarterectomy and a Lichtenstein repair for an inguinal hernia. The patient used acetylsalicylic acid and dipyridamole as anticoagulation. At the time of admission, the patient was in severe shock. Abdominal ultrasonography showed free intraperitoneal fluid in all quadrants of the abdomen. The following contrast-enhanced abdominal computed tomography (CT) revealed splenic injury with active venous contrast extravasation with high-density perisplenic and perihepatic fluid (Fig. 1). Thereby, there were gas configurations most likely due to a (micro)perforation of the colon at the splenic flexure (localization of polypectomy) (Fig. 2). The patient was resuscitated at the emergency department and transported to the operation room for further operative treatment. Embolization was not an option since there was venous active blood loss and colonic perforation.

During surgery, the spleen was indeed completely ruptured into 2 parts with active blood loss, and there was a (diathermic) microperforation of the colon without faecal spill. A splenectomy was performed, and then small splenic parts were implanted in the greater omentum. Thereafter, the colonic perforation was sutured, and the abdominal cavity was cleaned from blood clots. After surgery, the patient was admitted to our medium care unit 


\section{Case Reports in Gastroenterology} Case Rep Gastroenterol 2017;11:127-133
\begin{tabular}{l|l} 
DOI: 10.1159/000455940 & $\begin{array}{l}\text { @ 2017 The Author(s). Published by S. Karger AG, Basel } \\
\text { www.karger.com/crg }\end{array}$
\end{tabular}

Nallayici et al.: Shock due to Splenic Injury after Colonoscopy

and later to the general ward. He was discharged from the hospital 6 days after initial presentation. After splenectomy, vaccinations and prophylactic antibiotics were given.

\section{Discussion}

Colonoscopy is the golden standard in diagnosing colonic pathology. It is considered as a safe procedure, but complications do happen. Intraluminal bleeding (0.3-2.1\%) and colonic (micro)perforation $(0.1-2.5 \%)$ are the most common complications [1]. Rare complications are mesenteric tear, portal venous gas, pneumothorax, subcutaneous emphysema, pneumoscrotum, pneumomediastinum, septicaemia, incarceration of hernia, diverticulitis, appendicitis, volvulus, methane or hydrogen gas explosion, or injury of the spleen $[1,4]$.

Splenic injury after colonoscopy is a rare, yet potentially life-threatening complication. Only a few case reports and case series have been reported [4] since its initial description by Wherry and Zehner [2] in 1974. It has an incidence of around $0.00005-0.017 \%$ and a mortality rate of $5 \%$ [1]. $72-75 \%$ of the splenic injuries after colonoscopy occurred in female patients [1]. Guner et al. [5] concluded that its incidence is probably underestimated due to the fact that $77 \%$ of the splenic injury cases were published after the year 2000 , while colonoscopy was introduced in the 1960s. Due to the increasing and widespread use of colonoscopy, it will probably occur more frequently in the upcoming years [5]. In the current literature, multiple causes of splenic injury were described such as direct trauma during the passage in the colon through the splenic flexure or traction to the splenocolic ligament leading to an avulsion or a tear of the spleen. Other reasons for splenic injury are fibrous adhesions between the spleen and colon after pancreatitis, surgery, or inflammatory bowel disease [6]. 48-64\% of the patients have a history of abdominal surgery [5]. Splenomegaly, splenic disease, inflammation, colon cancer, anticoagulant therapy, and external pressure during colonoscopy, all contribute to a risk of splenic injury [4]. The use of intravenous sedation during colonoscopy has been suggested to increase the risk of splenic injury since patients cannot report pain associated with stretching of the splenocolic ligament [7]. Thereby, technical manoeuvres during colonoscopy such as the $\alpha$-manoeuvre, straightening of the sigmoid loop, and external pressure on the left hypochondrium may increase the risk of splenic injury [8]. This complication may be avoided with a left lateral position and minimizing the external pressure [6]. A higher incidence of splenic injury has been reported in therapeutic colonoscopies when biopsies or polypectomies were performed [1]. Our patient had no splenomegaly, but a difficult polypectomy was performed, and he did use anticoagulation therapy. Splenic rupture was most likely due to direct traction of the ligament during colonoscopy after polypectomy, possible exacerbated by the use of anticoagulation therapy (Fig. 3).

The symptoms at the time of admission depend on the severity of the injury. Our patient was observed to have haemodynamic instability and intraperitoneal haematoma due to massive intra-abdominal bleeding. Other symptoms were due to diaphragm irritation (Kehr's sign) and/or peritonitis. Our patient was admitted to the emergency department 2 days after the initial colonoscopy; the delay was probably caused by the late penetration of the haematoma through the spleen capsule. Most patients seek medical attention within the first $24 \mathrm{~h}[1,9,10]$. Radiological examination is essential for the diagnosis. A plain radio- 
graph of the abdomen can confirm a perforation. Ultrasonography or a contrast-enhanced CT scan are both reliable tools to diagnose free intra-abdominal fluid. The contrast-enhanced CT is considered the gold standard because it may also rule out injury to other organs and it offers the possibility of grading splenic injuries [11]. In our case, after an ultrasonography a contrast-enhanced CT scan was performed for a fast and prompt diagnosis.

Treatment options include observation, selective arterial embolization, or splenectomy; the options are based on the haemodynamic status, the type of blood loss (venous vs. arterial), and the option of the radiologist to perform selective arterial embolization. In the current literature, splenectomy is the treatment of choice since it is the most frequently used option with $56.1 \%[1,11]$ followed by conservative treatment with $27.3 \%$ [1] and embolization with $4.5 \%$ [1]. Conservative treatment is an option in haemodynamically stable patients [5]. Ha and Minchin [1] reported conservative treatment in $25 \%$ of the cases; patients were treated with bed rest, intravenous antibiotics, close haemodynamic monitoring, volume replacement, serial haemoglobin checks, and imaging. Ha and Minchin also reported that conservative management might require more transfusion than does operative intervention. Our patient was unstable; therefore, we performed an immediate splenectomy. Selective embolization was not a treatment option because of the venous aspect of the bleeding, although selective arterial embolization is a safe and effective treatment in elderly patients with comorbidity and in patients with anticoagulation therapy. The length of the hospital stay was similar to that in the case of surgical treatment [12].

\section{Conclusion}

Splenic rupture is a rare complication after colonoscopy. In the case of patients with abdominal pain and/or shock after colonoscopy, suspicion of splenic injury and other complications should be raised. According to the current literature, non-operative management is a safe treatment option in haemodynamically stable patients. However, with haemodynamic instability selective arterial embolization or surgical management may be required.

\section{Statement of Ethics}

The case patient agrees with the publication of this case report after informed consent.

\section{Disclosure Statement}

No conflicts of interest. No financial support.

\section{References}

1 Ha JF, Minchin D: Splenic injury in colonoscopy: a review. Int J Surg 2009;7:424-427. 


\section{Case Reports in Gastroenterology} \begin{tabular}{l|l}
\hline Case Rep Gastroenterol 2017;11:127-133 \\
\hline DOI: 10.1159/000455940 & $\begin{array}{l}\text { (c 2017 The Author(s). Published by S. Karger AG, Basel } \\
\text { www.karger.com/crg }\end{array}$ \\
\hline
\end{tabular}

Nallayici et al.: Shock due to Splenic Injury after Colonoscopy

2 Wherry DC, Zehner H Jr: Colonoscopic fiberoptic endoscopic approach to the colon and polypectomy. Med Ann Dist Columbia 1974;43:189-192.

3 Castelli M: Splenic rupture: an unusual late complication of colonoscopy. CMAJ 1986;134:916-917.

$\checkmark 4$ Brennan IM, Faintuch S, Sacks B: Superselective splenic artery embolization for the management of splenic laceration following colonoscopy. Acta Radiol Short Rep 2014;3:2047981614524199.

5 Guner A, Kaya U, Kece C, Kucuktulu U: Is non-operative management feasible for splenic injury due to colonoscopy? BMJ Case Rep 2013;2013:bcr2013009286.

6 McBride R, Dasari B, Magowan H, Mullan M, Yousaf M, Mackle E: Splenic injury after colonoscopy requiring splenectomy. BMJ Case Rep 2013;2013:bcr2013009126.

7 Pfefferkorn U, Hamel CT, Viehl CT, et al: Haemorrhagic shock caused by splenic rupture following routine colonoscopy. Int J Colorectal Dis 2007;22:559-560. Shatz DV, Divas LA, Doherty JC: Management options of colonoscopic splenic injury. JSLS 2006;10:239243.

9 Michetti CP, Smeltzer E, Fakhry SM: Splenic injury duo to colonoscopy: analysis of the world literature, a new case report, and recommendations for management. Am Surg 2010;76:1198-1204.

$\$ 10$ Fishback SJ, Pickhardt PJ, Bhalla S, et al: Delayed presentation of splenic rupture following colonoscopy: clinical and CT findings. Emerg Radiol 2011;18:539-544.

11 Hildebrand DR, Ben-Sassi A, Ross NP, Macvicar R, Frizelle FA, Watson AJ: Modern management of splenic trauma. BMJ 2014;348:g1864.

12 Corcillo A, Aellen S, Zingg T, Bize P, Demartines N, Denys A: Endovascular treatment of active splenic bleeding after colonoscopy: a systematic review of the literature. Cardiovasc Intervent Radiol 2013;36:1270-1279.

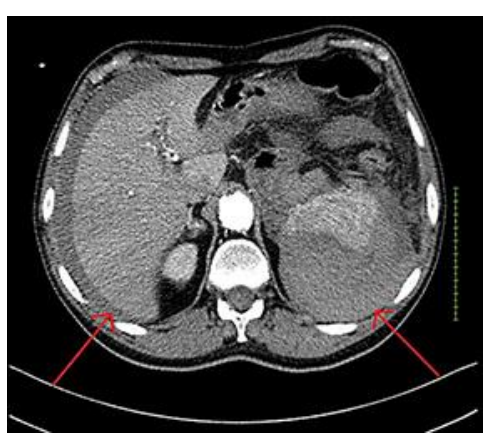

Fig. 1. CT scan of the abdomen. Perisplenic and perihepatic haematoma due to splenic injury (red arrows). 


\section{Case Reports in Gastroenterology}

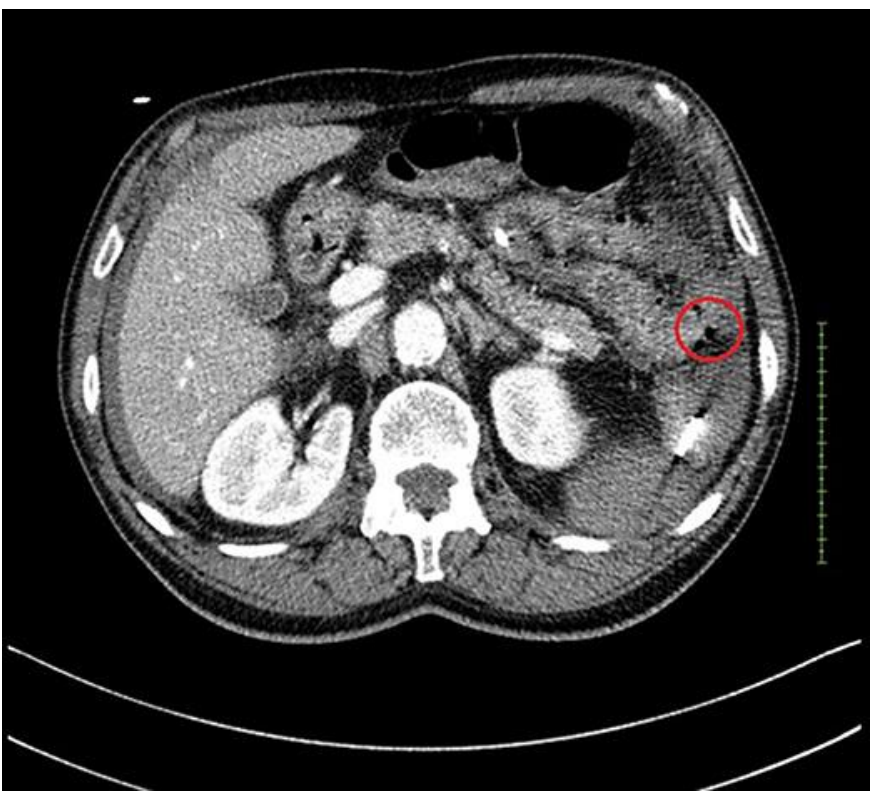

Fig. 2. CT scan of the abdomen. Free air due to colon perforation (red circle).

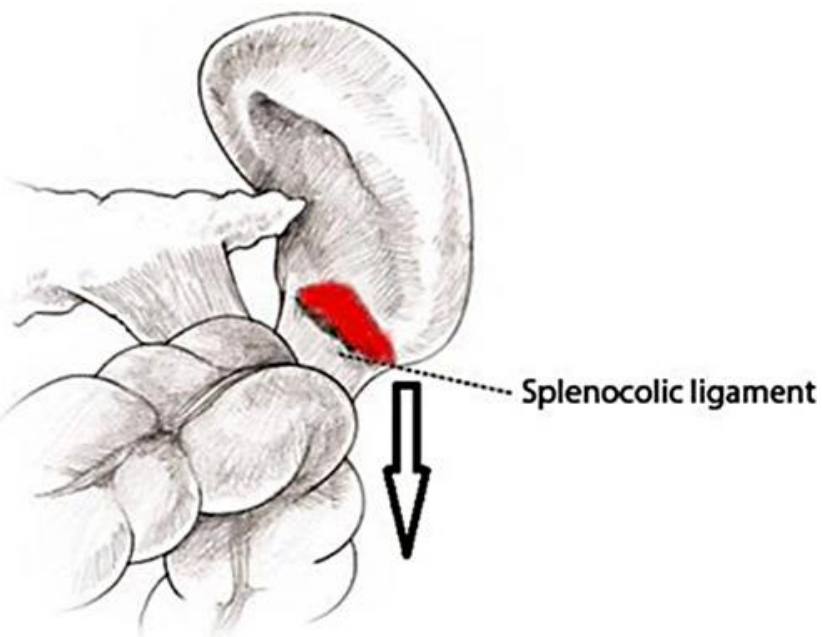

Fig. 3. Illustration. Aetiological mechanism of splenic injury; avulsion of the splenic capsule caused by excessive traction of the splenocolic ligament during manipulation of the colonoscope. 


\section{Case Reports in Gastroenterology}

\begin{tabular}{|c|c|}
\hline DOI: $10.1159 / 000455940$ & $\begin{array}{l}\text { (c) } 2017 \text { The Author(s). Published by S. Karger AG, Basel } \\
\text { www.karger.com/crg }\end{array}$ \\
\hline
\end{tabular}

Table 1. Laboratory findings on admission

\begin{tabular}{|c|c|c|c|c|c|}
\hline \multicolumn{3}{|c|}{ Blood count } & \multicolumn{3}{|c|}{ Biochemistry } \\
\hline WBC & $14.4 \times 10^{9} / \mathrm{L}$ & $4.0-10.0 \times 10^{9}$ & CRP & $39 \mathrm{mg} / \mathrm{L}$ & $<10$ \\
\hline $\mathrm{RBC}$ & $2.6 \times 10^{12} / \mathrm{L}$ & $4.5-5.5 \times 10^{12}$ & T-bil & $<17 \mu \mathrm{mol}$ & $<17$ \\
\hline $\mathrm{Hb}$ & $5.5 \mathrm{mmol} / \mathrm{L}$ & $8.5-11.0$ & AST & $6 \mathrm{U} / \mathrm{L}$ & $<40$ \\
\hline $\mathrm{Ht}$ & $0.28 \mathrm{~L} / \mathrm{L}$ & $0.40-0.50$ & ALT & $9 \mathrm{U} / \mathrm{L}$ & $<45$ \\
\hline \multirow[t]{9}{*}{ Plt } & $186 \times 10^{9} / \mathrm{L}$ & $150-400 \times 10^{9}$ & ALP & $42 \mathrm{U} / \mathrm{L}$ & $<125$ \\
\hline & & & $\gamma \mathrm{GTP}$ & $14 \mathrm{U} / \mathrm{L}$ & $<50$ \\
\hline & & & $\mathrm{LDH}$ & $104 \mathrm{U} / \mathrm{L}$ & $<250$ \\
\hline & & & Cre & $87 \mu \mathrm{mol} / \mathrm{L}$ & $65-105$ \\
\hline & & & $\mathrm{Na}$ & $146 \mathrm{mmol} / \mathrm{L}$ & $135-145$ \\
\hline & & & $\mathrm{K}$ & $4.3 \mathrm{mmol} / \mathrm{L}$ & $3.5-5.0$ \\
\hline & & & Lactate & $3.3 \mathrm{mmol} / \mathrm{L}$ & $0.5-1.7$ \\
\hline & & & CK & $36 \mathrm{U} / \mathrm{L}$ & $<171$ \\
\hline & & & cTnT & $20 \mathrm{ng} / \mathrm{L}$ & $<14$ \\
\hline
\end{tabular}

